\title{
Predicting Emotions and Meta-Emotions at the Movies: The Role of the Need for Affect in Audiences' Experience of Horror and Drama
}

\author{
Anne Bartsch ${ }^{1}$ Markus Appel $^{2}, \&$ Dennis Storch $^{3}$ \\ ${ }^{1}$ Zeppelin University Friedrichshafen \\ ${ }^{2}$ Johannes Kepler University Linz \\ ${ }^{3}$ Martin Luther University Halle
}

Bartsch, A. Appel. M., \& Storch, D. (2010). Predicting emotions and meta-emotions at the movies: The role of the need for affect in audiences' experience of horror and drama.

Communication Research, 37(2), 167-190. doi:10.1177/0093650209356441

The definitive version is available at http://crx.sagepub.com/content/37/2/167

This article may not exactly replicate the final version published in the previously mentioned Journal. It is not the version of record and is therefore not suitable for citation.

Acknowledgements: The authors wish to thank Peter Borkenau and Roland Mangold for their helpful comments on an earlier version of this article.

Funding: -

Corresponding author: anne.bartsch@zeppelin-university 


\begin{abstract}
Audiences are attracted to dramas and horror movies even though negative and ambivalent emotions are likely to be experienced. Research into the seemingly paradoxical enjoyment of this kind of media entertainment has typically focused on gender- and genrespecific needs and viewing motivations. Extending this line of research, the authors focus the role of the need for affect as a more general, gender- and genre-independent predictor of individual differences in the experience of emotions and meta-emotions (i.e., evaluative thoughts and feelings about one's emotions). The article discusses a field study of moviegoers who attended the regular screening of a drama or a horror film. Results support the assumption that individuals high in need for affect experience higher levels of negative and ambivalent emotions and evaluate their emotions more positively on the level of metaemotions. Controlling for the Big Five personality factors does not alter these effects. The results are discussed within an extended meta-emotion framework.
\end{abstract}

Keywords: Need for affect, emotion, meta-emotion, movie experience 
Predicting Emotions and Meta-Emotions at the Movies.

The Role of the Need for Affect in Audiences' Experience of Horror and Drama More than two thousand years ago, Aristippus of Cyrene speculated that the ultimate aim of human striving and behavior is to maximize pleasure and to minimize pain. Although the ethical implications have been a matter of controversy since its inception, the hedonistic principle has a long and distinguished history in the psychology of emotion (cf. Arnold, 1960, Lazarus, 1991; LeDoux, 2002). Most theories of emotion assume that individuals are motivated to seek and intensify pleasurable moods and emotions, and to avoid or modify unpleasant ones. This view of human emotion regulation has been highly influential in the field of media psychology as well, specifically in terms of mood-management theory (Zillmann, 1988). The notion that individuals' media choices are based on hedonistic needs and motivations has been tested successfully in a number of studies (for a recent overview see Knobloch-Westerwick, 2006).

However, despite its undoubted success, the hedonistic principle has also faced nontrivial challenges (cf., Oliver, 2007; Oliver \& Bartsch, in press). Considering audiences' taste for tales of tragedy and horror, the line dividing positive from negative affect is notoriously blurred. Research has repeatedly found that for certain members of the audience higher levels of negative affect are associated with higher levels of media enjoyment (David, Horton \& German, 2008; Oliver, 1993; Oliver, Weaver \& Sargent, 2000; Sparks, 1991; Zillmann, Weaver, Mundorf \& Aust, 1986). Thus, counter to the hedonistic default assumption, it seems that at times individuals are motivated to seek, indulge, and enjoy the experience of negative emotions such as fear or sadness (Mayer \& Gaschke, 1988; Oliver, 1993).

The purpose of our research is to further elucidate the experience of emotions and 
meta-emotions (i.e., evaluative thoughts and feelings about emotions) in horror and drama audiences. Both genres have been at the focus of research into the seemingly paradoxical enjoyment of negative emotions, however, little commonality has been found between them in terms of related needs and viewing motivations. To advance the development of a common explanatory framework, we considered the role of the need for affect (Maio \& Esses, 2001) as a more general predictor of individuals' engagement with emotional media experiences. Following an overview of theoretical concepts that deal with the enjoyment of negative emotions, the need for affect is introduced and related to this topic.

We conducted a field study of moviegoers who attended the regular screening of a drama or a horror film to examine the influence of the need for affect on the experience of emotions and meta-emotions in these audiences. The influence of the Big Five personality factors (Costa \& McCrae, 1992) is also considered to explore whether variance explained by the need for affect could be reduced to more basic personality factors. The results of this study are discussed within an extended meta-emotion framework.

Theoretical Background

Several authors have dealt with the seemingly paradoxical enjoyment of negative emotions in media use (e.g., Appel, 2008; Maio \& Esses, 2001; Oliver, 1993; Sparks, 1991; Tamborini \& Stiff, 1987; Zillmann, Weaver, Mundorf \& Aust, 1986). This line of research suggests that for certain individuals the experience of intense emotions such as fear or sadness is part of the gratifications associated with dramas and horror films. Sparks (1991) found that when males viewed a horror film, their levels of reported distress and skin conductance reactions were correlated with levels of enjoyment or delight. For females, distress and delight were unrelated (cf., Zillmann et al., 1986). In a similar vein, Oliver (1993) found that among individuals who scored high on sad film preference, the greater the reported sadness 
while watching dramatic film scenes the greater the reported enjoyment. Low scorers experienced the opposite. For them, sadness was inversely related to enjoyment (cf., Oliver et al., 2000). This pattern of results seems to suggest that for those who feel the most attracted to dramas and horror movies, the experience of negative affect is not just a byproduct or a necessary evil but rather an active ingredient of genre-related gratifications.

Research into personality factors that account for individuals' enjoyment of dramas and horror films has provided important insights into the role of personality in shaping emotional media preferences. For example, empathy and female gender role identification have been linked to sad film preference (Oliver, 1993), whereas male viewers and individuals who are high in sensation seeking, trait aggressiveness, and low in empathy typically reported more enjoyment of frightening and violent movies (for a recent meta-analysis see Hoffner \& Levine, 2005). Thus, existing research seems to imply that contrasting patterns of personality account for individuals' enjoyment of negative emotions depending on the genre and type of emotion. Broadly speaking, the taste for sad and tragic entertainment experience has been traced to "feminine" traits, and the enjoyment of fear and violence to "masculine" traits. This pattern of results is intuitively plausible as it conforms to familiar stereotypes of gendered media use. However, its explanatory power is limited in terms of common underlying mechanisms that might account for emotional viewing motivations across gender and genre boundaries.

\section{Emotions, Meta-Emotions, and Media Use}

The concept of meta-emotion discussed by Oliver (1993) has the potential to integrate this research and to provide a framework for studying the enjoyment of negative emotions in media use beyond the role of gender- and genre-specific patterns. Meta-mood (which is used largely synonymous with meta-emotion) is defined by Mayer and Gaschke (1988) as "the 
possible outcome of a regulatory process that monitors, evaluates, and changes mood" (p. 109). These authors distinguish between the experience and meta-experience of moods and emotions, and argue that individuals are able to direct pleasant thoughts and feelings at unpleasant moods, or vice versa. Based on this line of reasoning, Oliver (1993) proposed to solve "the paradox of the enjoyment of sad films" (p. 315) by considering individuals' taste for tragic entertainment a meta-emotion. She argued that other-directed forms of sadness such as empathy and pity are valued in our culture, especially as part of the female gender role, and are therefore associated with self-enhancing thoughts and feelings for individuals who identify with this ideal.

More generally speaking, the paradox of the enjoyment of negative emotions is resolved within the meta-emotion framework by considering not only the valence of primary emotions that evaluate the media content, but also the valence of meta-emotions that evaluate the emotions experienced in the process of media use. Just as primary emotions motivate individuals to maintain or change the emotion eliciting situation, meta-emotions motivate individuals to maintain or change their primary emotions. In light of this concept, the seeking, maintenance, and intensification of negative emotions are not in contrast with hedonistic assumptions if they are motivated by the positive valence of meta-emotions (cf., Bartsch, Vorderer, Magold \& Viehoff, 2008). ${ }^{1}$ The present research is based on this extended metaemotion framework that generalizes from Oliver's (1993) explanation of the sad film paradox to individuals' enjoyment of other kinds of affectively negative media experiences, including different kinds of emotions and media genres.

\section{The Need for Affect}

A recent concept that addresses meta-emotion in a wide sense, independent of the type of emotion and context, is the Need for Affect (Maio \& Esses, 2001). The need for affect 
(NFA) is defined as the "general motivation of people to approach or avoid situations and activities that are emotion inducing for themselves and others" (Maio \& Esses, 2001, p. 585). The authors' conceptualization of 'affect' is broad and includes moods, emotions, preferences, and related evaluations. It is assumed that individuals with a strong NFA are motivated to approach affect-laden situations, and appreciate the experience of emotions, whereas individuals who are low in NFA tend to avoid and dismiss emotional experiences. Thus, the NFA recommends itself as a predictor of individuals' motivation to engage in emotional media experiences including those that are negative or ambivalent.

Its operationalization, the Need for Affect Questionnaire, is composed of two subscales assessing individual's tendency to approach, and avoid emotions respectively. Two examples of items are: "I feel that I need to experience strong emotions regularly.", and "Emotions are dangerous - they tend to get me into situations that I would rather avoid." Of note, media use, or the preference for specific media genres are neither part of the definition nor part of the operationalization of the NFA. This secures that this construct as explanans is conceptually distinct from its explanandum, i.e., emotional experiences at the movies.

\section{The Need for Affect and Selective Exposure to Media Content}

In recent research, the NFA has been applied to predict selective exposure to emotional media experiences. In a study of Maio and Esses (2001) participants read descriptions of films that included information about how interesting, happy, and sad each film was supposed to be, and rated their willingness to see the film. These authors found that the willingness to watch emotional films (willingness to see happy and sad films minus willingness to see films that were neither happy nor sad) was higher for individuals with a strong NFA. In a similar study, Appel (2008) specifically addressed the intended exposure to media stimuli with affectively negative content. Film synopses included either positive, or 
negative emotional adjectives from the Positive and Negative Affect Schedule (Watson, Clark, \& Tellegen, 1988), or no emotional adjectives. For females NFA approach scores predicted the willingness to watch movies with affectively negative content, but not the willingness to watch movies with positive or neutral content. However, no significant effect was found for males in this study.

Overall, there is partial support for the notion that the NFA influences intended exposure to emotional media experiences, including (but not limited to) the experience of negative emotions. However, existing results are somewhat limited, considering the absence of a significant relationship in Maio and Esses' (2001) study between NFA and the willingness to watch sad films (if analyzed independently of the willingness to watch other kinds of films), and the gender-specificity of the effect for negative affect in Appel's (2008) study. Besides, these studies are limited by their reliance on hypothetic film descriptions rather than on actual movie experiences. Another more general limitation is the focus of these studies on intended exposure.

\section{The Need for Affect and Emotional Experience}

Research on individuals' intended exposure to media content provides a useful indicator of their willingness to use media offerings that they expect will have emotion eliciting effects. However, it leaves open important questions about audiences' actual experience of emotions within the process of media use. In line with the general notion that needs account not only for individuals' seeking of situations where need satisfaction is expected, but also for their experience and behavior within such situations, Maio and Esses (2001) predicted that, in addition to approaching emotion eliciting situations, individuals with a strong NFA are also more responsive to such situations as they occur. They analyzed selfreported affective, cognitive, and behavioral reactions to the death of Princess Diana in a 
British sample, and found that the NFA was related to the number of reported emotions, behaviors, and beliefs concerning this sad event. Individuals high in NFA also reported higher levels of negative valence when rating their responses. These results point to differences in individuals' engagement with and experience of emotion eliciting situations. Individuals with a strong NFA seemed to indulge and even actively dwell on negative emotions related to Diana's death, whereas individuals low in this trait tended to behave in such ways as to minimize their emotional reactions (e.g., by engaging in less thoughts and behaviors related to the event).

The dual role of the NFA as 1) a motivation to approach emotion eliciting situations, and 2) a motivation to get emotionally involved with such situations as they occur, can be explained more in-depth within the framework of emotion regulation theory. Gross and coworkers (Gross \& Thompson, 2007; John \& Gross, 2007) identified five emotion regulation strategies that can be employed at different stages of the emotion process to either amplify or reduce the affective outcomes of that process. In the case of the first two strategies, situation selection and situation modification, the person changes his or her exposure to emotion eliciting stimuli and events, whereas in the case of the remaining three strategies, attention deployment, cognitive reappraisal, and response modulation, the person adjusts his or her way of processing emotion eliciting stimuli and events in an ongoing exposure situation. Given that the NFA is conceptualized as a general motivation to seek the experience of intense emotions, individuals with a strong NFA can be assumed to use the full range of available regulation strategies to satisfy their emotional needs, including strategies to both enhance exposure to, and intensify their experience of emotion eliciting situations.

Thus far, research on the regulation of moods and emotions via media use has predominantly focused on selective exposure to media content. It is equally important, 
however, to consider individual differences in the experience of emotions during exposure in order to more fully understand how audiences' needs and attitudes toward emotions interact with the media stimulus to shape emotional outcomes. The NFA provides a useful concept for studying audiences' active role in emotional media experience, because it allows to make predictions about differences in both individuals' level of emotional responsiveness, and their meta-emotions, i.e., the extent to which emotions are perceived to be desired and gratifying.

\section{Ambivalent Affect}

Besides individuals' motivation to seek the experience of negative emotions, we also considered the influence of the NFA on ambivalent feelings. This facet of emotional experience which is characterized by a co-occurrence of positive and negative affective valence (Cacioppo \& Berntson, 1994) is not frequently addressed in communication research (but see, Edell \& Burke, 1987; Oliver, Limperos, Tamul \& Woolley, 2009). However, recent research using an extended version of the Differential Emotion Scale (Renaud \& Unz, 2006) indicates that, besides unambiguously positive and negative emotions, ambivalent feelings such as fascination, surprise, interest and being moved form a distinct factor in film-viewers' self-report of emotions. Likewise, Oliver et al. (2009) found that the experience of mixed affect (i.e., experiencing high levels of both positive and negative affect) was key in individuals' appreciation of serious dramas. Thus, we were interested to explore whether the experience of ambivalent emotions is predicted by the NFA as well.

In terms of underlying processes that give rise to ambivalent feelings, Cacioppo and Berntson's (1994) evaluative space model assumes that the affect system has two partially distinct components, "one attuned to nurturance and appetition (i.e., positivity), and the other attuned to threat and aversion (i.e., negativity)" (Larsen, et al., 2001, p. 686). Due to the partial independence of underlying neural processes, both affect systems can be coactivated. 
From within a meta-emotion framework, affective ambivalence can be assumed to occur in two forms: either because positive and negative emotions are coactivated on the level of primary emotions, or because emotions are accompanied with meta-emotions of opposite valence. To advance understanding of the ambivalent emotion factor, we aimed to explore its relation with other emotion variables, specifically positive and negative primary emotions, and meta-emotions.

\section{Rationale and Hypotheses}

Based on the above considerations, the present research had three main objectives: Our first aim was to broaden the scope of meta-emotion as an exploratory framework of emotional needs and viewing motivations across gender and media genres. We specifically addressed horror and drama, i.e., the two film genres traditionally at the heart of research into the enjoyment of negative emotions. Second, we aimed to extend the current focus of research on NFA and media use from intended exposure and hypothetic film descriptions to audiences' experience of emotions in actual exposure situations. Third, besides our focus on negative emotions we explored whether the experience of ambivalent feelings is predicted by the NFA as well, and how it is related to other emotion variables.

To address these research objectives we conducted a field study of emotions and metaemotions in moviegoers who watched either a drama or a horror film. We expected that the NFA predicts individuals' experience of emotions and meta-emotions in response to these movies. Specifically, we assumed that individuals high in NFA would experience higher levels of negative and ambivalent feelings, and that they evaluate their emotions more positively in terms of meta-emotions. The following approach was used to enhance external validity: first, we used full-length feature films as stimuli instead of hypothetic film descriptions. Second, we conducted a field study in a naturalistic exposure situation: 
participants were surveyed before and after a regular film screening at the movie theater. Third, we recruited participants who had come to see the movie on their own initiative. Though we are aware of methodological limitations associated with self-selection, we consider that self-determined exposure is an essential characteristic of naturally occurring media use. Conversely, the experience of a random sample presented with a drama or horror movie they would not have watched by choice may have relatively little in common with the experience of actual movie audiences.

Our hypotheses concerning the influence of the NFA on emotional experience were focused on the approach component of the NFA, because this aspect of the construct is directly related to the seeking of strong emotions. The NFA avoidance component, in contrast, is open to interpretations that are more ambiguous: it can be considered either as a motive to suppress emotions or as a motive to avoid emotion eliciting situations in the first place because of individuals' inability to regulate emotions effectively. Because the two possible interpretations of the avoidance component of the NFA have contradictory implications in terms of regulatory outcomes, we had no hypotheses concerning the influence of NFA avoidance on emotional experience. Thus, our hypotheses concerning emotional experience were focused on the approach component of the NFA.

First, we expected that when watching a drama or a horror film individuals with a strong NFA would be more willing to engage emotionally, and would therefore experience more intense emotions.

H1: Higher levels of NFA approach are associated with a higher reported intensity of emotions in response to a drama or horror film.

Second, we predicted that individuals with a strong NFA would experience higher levels of negative valence in response to the movies. This hypothesis reflects the finding of 
Maio and Esses (2001) that those who were high in NFA reported more negatively valenced reactions to the death of Princess Diana. In the case of the film genres under study, negative emotions seem to be the most suitable response as well (i.e., in the sense of a "preferred reading”, intended by the film-makers). Thus, individuals high in NFA approach motivation should be expected to experience higher levels of negative valence.

H2: Higher levels of NFA approach are associated with higher reported levels of negative valence in response to a drama or horror film.

Third, for similar reasons as with negative valence, we predicted that individuals with a strong NFA would experience higher levels of discrete negative emotions, as they should be more willing to engage emotionally with the predominantly negative content of the movies.

H3: Higher levels of NFA approach are associated with higher reported levels of discrete negative emotions in response to a drama or horror film.

No hypothesis was formulated concerning positive emotions, because the two film genres considered in this study are not usually supposed to elicit unambiguously positive emotions, thus, a floor effect for this facet of emotional experience was to be expected. However, we predicted the NFA would have an influence on the experience of ambivalent emotions. Two alternative lines of thought lead to this prediction: first, ambivalent feelings may result from the coactivation of positive and negative emotions, and individuals high in NFA should be more willing to engage in this complex and challenging type of emotional experience. Second, ambivalent emotions may result from the positive meta-experience of negative emotions, which should be more typical of individuals with a strong NFA. To evaluate the consistency of these two accounts for H4 with participants' self-report of emotions and meta-emotions, a research question was formulated, see RQ3 below.

H4: Higher levels of NFA approach are associated with higher reported levels of 
ambivalent emotions in response to a drama or horror film.

Predictions concerning the experience of meta-emotions were straightforward: individuals high in NFA should be particularly able to enjoy and value the experience of emotions elicited by the movies. Two facets of meta-emotion that are frequently mentioned in the meta-emotion literature were considered in the hypotheses: enjoyment of emotions and normative appreciation of emotions (cf., Bartsch et al., 2008; Mayer \& Gaschke, 1988;

Oliver, 1993). In the case of the meta-emotion variables, both NFA subscales were considered as likely predictors, because the generally positive or negative attitudes toward emotions reflected by the two subscales should translate into corresponding evaluations of the specific emotions experienced in response to the films.

H5: Higher levels of NFA approach and lower levels of NFA avoidance are associated with higher reported levels of meta-emotion enjoyment in response to a drama or horror film.

H6: Higher levels of NFA approach and lower levels of NFA avoidance are associated with higher reported levels of meta-emotion normative appreciation in response to a drama or horror film.

In addition to the hypotheses we examined further research questions. First, we expected that individual differences in the NFA predict the experience of emotions and metaemotions in both men and women, and regardless of film genre. Thus, we examined whether the expected effects differ for female vs. male participants (RQ 1). Further, we explored whether these effects differed for the two film stimuli, a drama and a horror film (RQ 2).

A third research question addressed two potential sources of affective ambivalence mentioned above: If ambivalent feelings arise from the coactivation of positive and negative emotions then they should be related to the experience of both positive and negative primary emotions. Alternatively, if ambivalent feelings result from the positive meta-experience of 
negative emotions, then they should be correlated with negative primary emotions and positive meta-emotions (RQ 3).

Although research that has employed the NFA in studies on attitudes and persuasion yielded promising results (e.g., Appel \& Richter, under review; Huskinson \& Haddock, 2004; Haddock, Maio, Arnold \& Huskinson, 2008) one may doubt its added value compared to well established constructs and measures such as general personality traits. The Big Five personality factors (Costa \& McCrae, 1992) are the most common taxonomy used to describe personality on a broad level, including the factors extraversion, neuroticism, openness to experience, agreeableness, and conscientiousness. Although these factors are rather unspecific, they have been successfully employed to predict the experience and regulation of emotions (John \& Gross, 2007; Matsumoto, 2006). Thus, the validity of the NFA as an explanatory variable of individual differences in emotional media experience would be strengthened, if it could explain variance that is not accounted for by the Big Five (RQ 4).

\section{Pilot Study}

A pilot study was conducted to test the self report measures for the emotion and metaemotion variables. The stimulus was an experimental hard rock music video that included a large spectrum of affective cues we expected to be evocative of negative emotions such as anger, fear, disgust, and pity. Fifty-three participants watched the music video, and reported their emotions and meta-emotions in response to the video. The pilot study questionnaire included a modified version of the Differential Emotion Scale (DES, Izard, Dougherty, Bloxom, \& Kotsch, 1974). The Modified Differential Affect Scale (MDAS) was developed by Renaud and Unz (2006) in an effort to incorporate a broader range of media-specific emotions, specifically, amusement, contentment, affection, fascination, being moved, and boredom. Previous research using the MDAS indicated that variance in MDAS scores is 
attributable to three broad factors that can be interpreted as positive, negative and ambivalent emotions (Unz, 2006). The results of our pilot study were in line with this factor structure. A principal axes factor analysis with non-orthogonal Promax-rotation $(\kappa=4)$ yielded a threefactor solution with eigenvalues of 11.9, 8.0, 3.6, 2.1, 1.5 and 1.5 for the first six factors. The three factors explained $57.3 \%$ of the variance. As expected, the MDAS items were related to three latent factors representing negative emotions (sadness, anger, fear, disgust, contempt), ambivalent emotions (fascination, surprise, interest, being moved), and positive emotions (amusement, joy, contentment).

In addition, the pilot study questionnaire included an item-pool of thirty-six positive and negative statements about emotions designed to assess participants' meta-emotions about the feelings elicited by the music video. Included in the item-pool were items referring to both enjoyment and normative appraisal of emotions. The existing operationalization of state metamood by Mayer and Gaschke (1988) is not sensitive to the distinction between these two facets of meta-emotion, therefore, the pilot study item-pool was designed in an effort to tease these two aspects apart. A principal axes factor analysis with oblique rotation (Promax, $\kappa=4$ ) yielded a two-factor solution with eigenvalues of 14.9, 4.3, 2.4, 1.8, 1.4 and 1.2 for the first six factors. The two factors accounted for $53.2 \%$ of the variance. As expected, the two latent factors represented items that expressed how good/bad the emotions elicited by the movie felt (meta-emotion enjoyment), or how the normative appropriateness of having such emotions was evaluated (meta-emotion normative appreciation).

Summarizing the results of the pilot study, the items used to measure emotions and meta-emotions yielded the expected factor structure. Hence, the MDAS and the newly developed meta-emotion items were considered to provide adequate operationalizations of the emotional experience variables addressed in the hypotheses. 


\section{Main Study: At the movies}

The main study was conducted in a field setting at a movie theater with a predominantly non-student sample. Unlike previous studies on NFA and media use that were based on individuals' ratings of hypothetic film descriptions, we used full length feature films as stimuli. One of the movies was a horror/thriller, and the other was a drama/history film (genre categorization based on internet movie database ratings).

\section{Method}

\section{Participants}

One-hundred and nineteen participants (68 female, 51 male) were recruited at a typical multiplex cinema in Germany. Potential participants were approached by a male researcher as they entered the building. They were asked which movie they planned to see. People who intended to watch one of the targeted movies were offered free tickets in return for their participation. The volunteers were between 17 and 58 years old. Their mean age was 23 years $(S D=9.6)$. About half of the sample (59 persons) were in the process of completing or had completed secondary school matriculation to the level of university entrance qualification, the remaining half (60 persons) had completed a maximum of 10 years of school education. In terms of occupation, 68 participants were employed or self-employed, 50 participants were attending secondary or tertiary education. Among the latter, six participants were university students. No further compensation was provided apart from the free tickets for the movie they wanted to see.

\section{Procedure}

On their way to the auditorium, the movie-goers who volunteered to take part in the study received a booklet with the instructions and the questionnaires. The booklet had two parts. The first part included the personality measures (NEO-FFI and NFA). Participants were 
seated in a quiet section of the foyer reserved for study participants. They completed the first part of the booklet, then proceeded to the auditorium and watched the movie.

After the movie, participants returned to the foyer and completed the second part of the booklet which consisted of the emotional experience measures (arousal, valence, discrete emotions, meta-emotions) and further items unrelated to the present topic. After finishing the second part of the booklet, the participants were thanked and debriefed.

\section{Stimuli}

We investigated emotional reactions to the movies United 93 (Greengrass, 2006) and The Omen (Moore, 2006). United 93 is a semi-fictional drama about the fourth terrorist attack plane that crashed on September 11, 2001 in a field in Pennsylvania. The movie portrays the passengers who learn about the background of the hijacking and try to prevent the terrorist attack, as well as military and government activities on the ground. The Omen (2006) is a remake of the same-titled horror film from 1976. The movie is about a boy who turns out to be the Anti-Christ aiming for a global Armageddon. The main characters include the boy's parents who struggle to defend the world from their child. We took care to select films that we thought would equally appeal to males and females in order to avoid gender biases in the sample. Unlike more gender-typed exemplars of their respective genres such as "slasher" movies for male or "weepie" movies for predominantly female audiences, both movies attracted female and male audiences alike. Fifty-four participants watched The Omen (25 male, 29 female), 65 participants watched United 93 (26 male, 39 female).

\section{Personality Variables}

Need for affect. The German language version of the Need for Affect Questionnaire (Appel, 2008) consists of 26 items (approach and avoidance subscales with 13 items each, for example: "I approach situations in which I expect to experience strong emotions") 
accompanied by a 7 -point scale (from $-3=$ strongly disagree to $+3=$ strongly agree). A principal axes factor analysis with Promax-rotation $(\kappa=4)$ yielded the expected two-factor solution (emotion-approach and emotion-avoidance). The reliability of the NFA scale was satisfactory with Cronbach's $\alpha=.87$ for the approach subscale and Cronbach's $\alpha=.85$ for the avoidance subscale. Affect approach and avoidance motivation were moderately related $(\mathrm{r}=-$ $.43, \mathrm{p}<.001)$.

Big Five personality traits. The German language version of the NEO-FFI (Borkenau \& Ostendorf, 1993) was employed to assess the Big Five personality traits. Assessment of the five personality dimensions was reliable, except for the agreeableness dimension, as indicated by the internal consistencies of the items (neuroticism Cronbach's $\alpha=.82$, extraversion $\alpha=$ .71 , openness $\alpha=71$, agreeableness $\alpha=.57$, and conscientiousness $\alpha=.84$ ). The scores on the Big five dimensions were virtually unrelated (all $|r| \mathrm{s}<.10$ ). Extraversion was associated positively with NFA approach $(r=.40 ; p<.001)$ and negatively with NFA avoidance $(r=-$ $.36 ; p<.001$ ), a similar pattern was found for openness (approach: $r=.30, p<01$; avoidance: $r=-.21, p<.05)$. Neuroticism was positively associated with both NFA approach $(r=.23, p$ $<.05)$ and NFA avoidance $(r=.35, p<.001)$. These relationship patterns fall in line with those of earlier studies (Maio \& Esses, 2001; Appel, 2008).

\section{Emotion Variables}

This part of the questionnaire instructed participants to "recall an event in the movie that elicited particularly strong emotions" in them, to briefly describe that event, and to focus on their experience of the event when completing the subsequent rating tasks. This instruction was used to obtain self-reports that reflected peaks of subjective emotional experience, taking into account that the most intense emotions may occur at different points of the movie for different individuals. Despite potential limitations associated with self-report and selective 
recall (see discussion section), we considered this procedure as a useful proxy for assessing the most salient and intense emotions experienced throughout the movie. A second rationale for focusing the self-report of emotions on a specific event in the movie was to facilitate the subsequent self-report of meta-emotions, because we assumed that the assessment of metaemotions is more reliable if the unit of self-report is a limited and emotionally salient episode in the movie rather than the emotional movie experience as a whole.

Intensity and valence of emotions. Two single items assessed basic dimensions of emotional experience, intensity and valence (cf. Lang, 1980; Mayer \& Gaschke, 1988). One item assessed the intensity of the emotional reaction ("How strong were the feelings this scene evoked in you") on a five-point-scale from very weak (1) to very strong (5). A second item addressed the valence of emotions ("Were these feelings positive or negative?") on a five-point-scale from very negative (1) to very positive (5).

Discrete Emotions. Emotional responses were assessed using the Modified Differential Affect Scale (MDAS, Renaud \& Unz, 2006). The MDAS consists of fourteen emotional states represented by three items each (e.g., I felt ... angry, I experienced ... joy). The items were rated on a 5-point scale ranging from not at all (1) to very much (5). A principal axes factor analysis with non-orthogonal rotation (Promax, $\kappa=4$ ) yielded a threefactor solution with eigenvalues of $8.7,5.8,3.6,2.0,1.9$, and 1.5 for the first six factors. The three factors explained $44.1 \%$ of the variance; they were interpreted as negative emotions (substantial loadings for items of the subscales sadness, anger, fear, disgust, contempt), ambivalent emotions (fascination, surprise, interest, being moved), and positive emotions (amusement, joy, contentment). Items of the subscales affection and boredom had low loadings on all three factors and were excluded from further analyses. This factor solution reflects results of Unz (2006) as well as the results of our pilot study. The reliabilities of all 
three emotion scales were good as indicated by Cronbach's $\alpha=.90$ (negative emotions, 15 items), Cronbach's $\alpha=.86$ (ambivalent emotions, 11 items), and Cronbach's $\alpha=.86$, (positive emotions, 9 items).

An inspection of the descriptive data showed a mean score for negative emotions of $M$ $=2.40(S D=0.81)$ and a mean score of ambivalent emotions of $M=2.90(S D=0.80)$. The participants reported very few positive emotions. Over two thirds scored below $M=1.50$ on a Likert scale ranging from one to five with a mean of $M=1.42(S D=0.50)$. Regardless of gender or movie seen, positive emotions were almost absent. Thus, as expected, the movies did not elicit positive emotions of joy, amusement, and contentment in the audience.

Meta-emotions. Like in the pilot study, thirty-six items were used to assess metaemotions. The items were rated on a five-point scale, ranging from do not agree (1) to completely agree (5). A factor analysis with non-orthogonal rotation was conducted (principal axes with Promax-rotation, $\kappa=4)$. The data analysis and a subsequent inspection of the solutions yielded two factors (eigenvalues of 14.0, 3.4, 2.0, 1.4, 1.3, and 1.2 for the first six factors) which accounted for $48.5 \%$ of the variance. As in the pilot study, the first factor meta-emotion enjoyment included items that express how good or bad it had felt to have the primary emotions (two highest loading items: "I like this feeling", "It was a pleasure to experience these feelings"). Items with high loadings on the second factor meta-emotion normative appreciation expressed normative acceptance of emotions (two highest loading items: "There is nothing wrong with feeling the way I did", "I find these feelings embarrassing"). Items with factor loadings $>.40$ and no substantial loading on the other factor were assigned to each factor. Meta-emotion enjoyment was represented by 20 items (Cronbach's $\alpha=.95)$, meta-emotion normative appreciation were represented by 11 items (Cronbach's $\alpha=.79$ ). For each aspect of meta-emotion, the items' raw scores were averaged 
(meta-emotion enjoyment: $M=2.98, S D=0.91$; normative appreciation: $M=4.09, S D=$ 0.57). Scores for both meta-emotional dimensions were moderately related $(r=.47, p<.001)$. Zero-order correlations between the primary emotion variables and the meta-emotion variables are displayed in Table 1. The two meta-emotion scales show distinct relationships with the primary emotion variables which are low to moderate in size.

$<$ Table 1>

\section{Results}

Hierarchical regression analyses were conducted to test the hypotheses. In a first step, the main effects of the predictor NFA were examined. The subscales emotion approach and emotion avoidance were entered simultaneously as predictors. Subsequently the main effects of gender, and the movie seen were included, together with all two-way, three-way, and fourway interaction terms, in order to test for potential moderation effects of gender (RQ1), and of the movie seen (RQ2). Regression coefficients in the complete equation are reported. Weighted effects codes were used for the categorical variables gender $(1=$ male, $-0.75=$ female $)$ and movie seen $(1=$ The Omen, -0.83 = United 93 $)$, which followed the calculus of $\mathrm{n}_{1} / \mathrm{n}_{2}$ (cf. Cohen, Cohen, West \& Aiken, 2003). The continuous predictors were $z-$ standardized. For all significance tests reported here, type-I-error probability was set to .05 . Primary Emotions

Hypothesis 1 assumed that the NFA explains the reported intensity of emotions experienced during the movie. As expected in our first hypothesis, higher scores in NFA approach are related to more intense emotions, $B=0.46, S E B=0.10, \beta=0.46, t=4.5, p<$ .001 . To explore research questions 1 and 2, a subsequent step in the regression analysis investigated whether or not the results differed for participants' gender, or for the movie seen. Gender or the movie seen had no direct effect on the intensity of emotions nor did interactions 
influence the results $(|t| \mathrm{s}<1.7, p \mathrm{~s}>.10)$.

Next, we analyzed the influence of NFA on the second general dimension of emotional experience, the valence of emotions experienced while watching the movies (Hypothesis 2). As expected, higher scores in NFA approach were related to higher levels of negative valence, $B=-0.26, S E B=0.10, \beta=-0.30, t=-2.6, p<.05$. Thus, feelings of individuals with a strong NFA were more negative than feelings of those with less emotional needs. Gender or the movie seen or related interactions did not influence this result $(|t| s<1.3$, $p s>.10)$.

Further, the influence of the NFA on the experience of two types of discrete emotions, negative and ambivalent emotions was analyzed. Hypothesis 3 assumed that the reported level of discrete negative emotions (sadness, anger, fear, disgust, contempt) while watching the movies is predicted by the NFA. The mean score of negative MDAS emotions was employed as the criterion. As expected, higher scores in NFA approach were related to higher levels of discrete negative emotions, $B=0.28, S E B=0.09, \beta=0.35, t=3.2, p<.01$. Again, we looked at differences in the results depending on gender, the movie seen, and related interactions. Gender did not influence the experience of discrete negative emotions $(|t|<1.0, p>.60)$. There was a main effect for the movie seen $B=-0.28, S E B=0.09, \beta=-0.32, t=-3.1, p<.01$. United $93(M=2.60 ; S D=0.79)$ evoked higher levels of negative emotions than The Omen $(M=2.16 ; S D=0.78)$. However, the movie did not moderate the relationship between NFA approach and the experience of negative emotions, nor was any other interaction effect significant $(|t| \mathrm{s}<1.0, p \mathrm{~s}>.30)$.

Hypothesis 4 assumed that the reported level of ambivalent emotions (fascination, surprise, interest, being moved) while watching the movies is predicted by the NFA. In accordance with our hypothesis, higher scores in NFA approach were related to higher levels 
of ambivalent emotions, $B=0.47, S E B=0.08, \beta=0.59, t=5.8, p<.001$. There were no main effects for gender and the movie seen $(|t| \mathrm{s}<1.1, p \mathrm{~s}>.30)$, however, we found a significant NFA approach by gender interaction $(B=-0.18, S E B=0.09, \beta=-0.20, t=-1.9, p=.050)$. Simple slope analyses (using dummy-coding of the categorical moderator, cf. Cohen et al., 2003) indicate that the relationship between NFA approach and the experience of ambivalent emotions was prevalent in both genders, i.e. among men $(B=0.29, S E B=0.11, \beta=.37, t=$ $2.7, p<.01)$, and, to a larger extent, among women $(B=0.61, S E B=0.12, \beta=.76, t=5.2, p<$ $.001)$. No other interaction effects approached statistical significance $(|t| \mathrm{s}<1.5, p \mathrm{~s}>.10)$.

\section{Meta-emotions}

Whereas the preceding hypotheses focused on the experience of primary emotions, hypotheses five and six addressed thoughts and feelings about emotions experienced while watching the movie. Hypothesis 5 predicted that these emotions are perceived as being more enjoyable among individuals high in NFA. In line with our hypothesis, higher scores in NFA avoidance were associated with more negative meta-emotions, $B=-0.30, S E B=0.10, \beta=$ $0.33, t=-3.0, p<.01$. However, there was no relationship between higher scores in NFA approach and meta-emotion enjoyment, $B=0.04, S E B=0.10, \beta=0.04, t=0.4, p>.10$. Although trait avoidance of emotions leads audiences to experience horror- and drama-related emotions as more aversive, the reverse is not true for the NFA approach component, i.e. trait approach of emotions does not result in more enjoyment of these emotions. The relationship between NFA avoidance and less enjoyment of emotions holds for both movies and both genders (all additional effects $|t| \mathrm{s}<1.5, p \mathrm{~s}>.10$ ).

Hypothesis 6 predicted a relationship between NFA and normative appreciation of emotions experienced while watching the movie. Higher scores on NFA approach were associated with a more positive evaluation of emotions, $B=0.17, S E B=0.06, \beta=0.30, t=$ 
$2.8, p<.01$. Likewise, higher scores on NFA avoidance were associated with a more negative evaluation of emotions, $B=-0.15, S E B=0.06, \beta=-0.25, t=-2.5, p<.05$. The relationship of both NFA subscales with participants' normative acceptance of emotions did not vary depending on gender or on the movie seen (all $|t| \mathrm{s}<1.5, p \mathrm{~s}\rangle .10$ ). Jointly, the results for the two hypotheses dealing with meta-emotions support the predictive validity of the NFA concerning audiences' meta-experience of drama- and horror-related emotions. Individuals who are high in NFA approach tended to experience their emotions as being more normatively adequate, and individuals high in NFA avoidance found their emotions to be less enjoyable and less normatively adequate.

\section{Additional Analyses}

In addition to the analyses addressing the hypotheses and research questions 1 and 2 we explored further research questions. RQ3 considered two alternative assumptions concerning ambivalent emotions: participants' self-report of ambivalent emotions could either reflect blends of positive and negative emotions, or the positive meta-experience of negative emotions. In the first case, ambivalent emotions should be correlated with both positive and negative emotions, in the second case, they should be correlated with negative emotions and positive meta-emotions. Ambivalent emotions were positively associated with discrete negative emotions $(r=.32, p<.001)$, as well as with both aspects of meta-emotion $(r=32, p$ $<.001 ; r=.23, p<.05$, see Table 1$)$. Ambivalent emotions were only marginally related to positive primary emotions $(r=.17 ; p=.06)$. Thus, our results were in support of the second assumption: participants' self-report of ambivalent emotions seemed to reflect a positive metaexperience of negative emotions.

Our fourth research question (RQ4) asked about the added value of the NFA compared to such well established personality measures as the Big Five. To explore whether the 
variance explained by the NFA can be reduced to more basic personality factors, we conducted hierarchical regression analyses with the emotion and meta-emotion variables as the criteria, and the following predictors: movie seen and gender (step 1), the Big Five personality traits (step 2), the NFA scales (step 3), and all interactions between movie, gender, and the NFA scales (step 4). This analysis yielded results of the predictive power of the NFA when gender, the movie seen, and the Big Five are statistically controlled for. Moreover, we can see in which ways the Big Five personality dimensions were related to the experience of emotions and meta-emotions. Table 2 shows the results for the complete equation. All effects of the NFA scales that were reported before remain substantial and significant in models that additionally include the Big Five personality traits. These additional analyses suggest that the influence of the NFA on the experience of emotions and meta-emotions goes beyond the information already included in general personality traits.

$<$ Table 2>

Looking at the effects of these general personality factors in detail, extraversion and neuroticism were related to the experience of ambivalent emotions $(t=3.5, p<.01 ; t=2.1, p$ $<.05)$. Agreeableness was related to the experience of negatively valence $(t=-2.2, p<.05)$, and to less enjoyment of emotions on the level of meta-emotions $(t=-2.3, p<.05)$. Conscientious viewers reported more intense emotions $(t=2.9, p<.05)$ as well as higher levels of discrete negative emotions $(t=2.4, p<.05)$. They were less affirmative with their feelings, both with regard to the enjoyment of emotion $(t=-2.5, p<.05)$ and their normative evaluation $(t=-2.2, p<.05)$.

Finally, we analyzed a potential influence of the NFA on the film scenes participants selected for the rating task. Remember that participants were requested to recall a scene that elicited particularly strong emotions in them, and to report on their responses to this scene. 
We did not expect that the NFA would have an influence on which scenes were recalled as particularly emotional, however, we conducted additional analyses using participants' open ended descriptions of the scenes to explore this possibility. In the case of United 93 the scenes could be categorized into 1) events related to the hijacking of the plane by the terrorists, 2) cell phone calls of the passengers to their relatives, 3 ) other scenes. We coded the open ended answers using these categories (20 participants selected a hijacking scene, 15 participants selected a phone call scene, and 18 participants selected other scenes), and conducted a multinominal logistic regression analysis with both NFA scales as predictors and the scene reported as the criterion. Results suggested that the NFA did not influence the selection of film scenes, all Wald $\chi^{2}(1)<0.7, p>.40$, Omnibus $\chi^{2}(4)=1.0, p>.90$, Nagelkerke $R^{2}=02$. In the case of The Omen, participants reported a number of different scenes. However, all scenes described were similar in that they referred to suspenseful events. Like most horror movies The Omen includes a chain of suspenseful episodes in which the audience is made to expect mischief for one or more of the protagonists. Because no more than 10 participants chose the same events we were unable to perform a quantitative analysis to predict the scenes selected. Taken together, we found no indication that the scenes recalled as having a strong emotional impact differed among individuals high vs. low in NFA.

\section{Discussion}

We conducted a field study of emotions and meta-emotions during exposure to a film, either drama or horror, in a naturalistic viewing situation at the movies. Results support the notion that individuals with a strong NFA are motivated to respond in ways that amplify their experience of negative and ambivalent emotions, and that they tend to evaluate their emotions more positively on the level of meta-emotion compared to individuals low in NFA. As expected, the NFA approach scale predicted all of our four emotion variables. Individuals 
high in NFA approach reported higher levels of discrete negative emotions and ambivalent emotions, and experienced higher levels of emotional intensity and negative valence. This pattern of results is in line with the finding of Maio and Esses (2001) that individuals with a strong NFA reported more negatively valenced reactions to the death of Princess Diana. The present study shows that the influence of the NFA on the experience of emotions generalizes from a real event to different kinds of fictional or semi-fictional media content, and from negative valence to a more comprehensive set of emotion variables, thus substantiating the assumption that individuals with a strong NFA are more emotionally responsive (cf., Haddock et al., 2008; Maio \& Esses, 2001).

Besides heightened levels of emotional reactivity we found evidence that the NFA was related to a more positive evaluation of emotions in terms of meta-emotion. Individuals high in NFA approach perceived their emotions to be more normatively adequate, and individuals high in NFA avoidance perceived their emotions to be less enjoyable and less normatively adequate. Thus, our study links the NFA as a trait measure of meta-emotion to the actual experience of meta-emotion as a state variable, thereby adding further detail to the construct validity of the NFA, and substantiating its integration into a meta-emotion framework.

By linking individuals' motivation to approach emotion eliciting situations to heightened emotional responsiveness, and a positive meta-experience of emotions, the NFA offers a promising concept for future research on emotional viewing motivations in general, and individuals' appreciation of negative and ambivalent feelings in particular. Moreover, the NFA may advance our understanding of individual differences in emotional media effects in the context of health communication (e.g., Lee, Hwang, Hawkins, \& Pingree, 2008; Shen \& Dillard, 2007), and narrative persuasion (e.g., Appel \& Richter, 2007; Green \& Brock, 2000). The Place of Gender- and Genre-Independent Effects Within the Meta-Emotion Framework 
None of the reported correlations of the NFA with the experience and meta-experience of emotions was dependent on participants' gender (except for ambivalent emotions, with a significant correlation in men, and an even stronger correlation in women), or on the movie they had seen. This indicates that the results can be generalized to an encouraging degree. High levels of NFA are associated with higher levels of emotional involvement and more positive meta-emotions in both men and women, and in both drama and horror audiences. To our knowledge, the NFA is the first personality trait studied in the research literature that seems to qualify as a consistent predictor of individuals' engagement with negative and ambivalent emotion experiences across gender and film genres, thus highlighting commonalities in underlying needs and viewing motivations.

The commonalities we found in the influence of the NFA on emotions and metaemotions in drama and horror audiences can be explained and integrated with existing research within an extended meta-emotion framework (cf., Oliver, 1993; Bartsch et al., 2008). This framework assumes that all emotions, including those that are negative and ambivalent, can be gratifying if they are accompanied with positive thoughts and feelings on the level of meta-emotion. The concept of meta-emotion covers different levels of specificity in individuals' appraisal of emotions: 1) attitudes toward emotions in general (e.g., the NFA), 2) attitudes toward specific emotions (e.g., sad film preference, cf. Oliver, 1993), and 3) flexible appraisal of emotions depending on the situation (e.g., mood-adjustment, cf., KnoblochWesterwick \& Alter, 2006). Our study addressed the influence of attitudes toward emotions in the most general sense. The results are not in contrast, however, with the assumption of gendered attitudes toward specific emotions, or situational factors that influence the perceived adequacy or gratification potential of emotions. Rather, we assume that attitudes and appraisals on all three levels of specificity contribute to the meta-experience of emotions and 
resulting viewing motivations.

The Role of Ambivalent Feelings in Individuals' Media Experience

The near complete absence of positive emotions such as joy, amusement, and contentment among the moviegoers who participated in our study underscores the need to explore further the gratification potential of negative and ambivalent feelings. In particular, it seems worthwhile to extend the focus to include affective ambivalence in audiences' response to entertainment. Among the three types of emotion words that served as self-report items in our study (positive, negative, and ambivalent feelings), ambivalent items received the highest rating scores, suggesting that participants perceived them as apt descriptors of their movie experiences. Still, the experience of affective ambivalence is largely uncharted territory in communication research. To add to this emerging research topic (cf., Edell \& Burke, 1987; Larsen et al., 2001, Oliver et al., 2009), we analyzed the relationship of the ambivalent emotion factor with other emotion variables. We found that ambivalent feelings were related to the experience of negative primary emotions, and positive meta-emotions, but were only marginally related to positive primary emotions. This seems to suggest that participants' selfreport of ambivalent feelings reflected the positive meta-experience of negative emotions.

However, alternative explanations of the ambivalent emotion factor are possible. Previous research has found that watching heart-warming advertisements, tragicomedies, and dramas elicited blends of positive and negative emotions, specifically sadness and joy (Edell $\&$ Burke, 1987; Larsen et al., 2001; Oliver et al., 2009). Although the relation of the ambivalent factor with positive emotions was only marginally significant, this explanation is also compatible with our results. Another potential explanation is that the ambivalent emotion factor reflects a sense of emotional intensity that can be associated with both positive and negative emotions (cf., Zaleski, 1984). Our finding that the ambivalent factor was related to 
emotional intensity is in line with this alternative account. Finally, the ambivalent emotion factor may reflect complex blends of affect and cognition as proposed by Oliver et al. (2009) based on their finding that the experience of mixed affect was related to the experience of "meaningful affective states" (including such items as tender, sentimental, contemplative and introspective). The items that formed the ambivalent factor in our study (fascination, interest, surprise, and being moved) seem to share this focus on blends of affect and cognition. We hope that future research will continue to explore these interesting theoretical options, and will further elucidate the nature and function of mixed and ambivalent feelings in media use. How Specific is the Pattern of Influence of the Need for Affect?

Additional regression analyses including the Big Five personality traits showed that the correlation of the NFA with audiences' experience of emotions and meta-emotions remained substantial and significant when the influence of the Big Five was statistically controlled for. Thus, the specific pattern of influence of the NFA on individuals' experience of emotions and meta-emotions in media use cannot be explained by these more basic personality factors. We hope that future research will also address the potential overlap of variance explained by the NFA with more fine-grained personality variables. For example, sensation seeking (Zuckerman, 1994) which is defined as "the seeking of varied, novel, complex and intense sensations and experiences [...]" (p. 27) is conceptually similar to the NFA. However, results of Maio and Esses (2001) indicate that it is empirically distinct. They found that sensation seeking was unrelated to NFA approach, and had a small negative correlation with NFA avoidance (cf., Appel, 2008). However, especially in the case of horror films, it would be useful to consider sensation seeking as a more fine-grained control variable to further substantiate the distinctiveness of the NFA as an explanatory variable of individual differences in emotional media experience. 


\section{Limitations and Outlook}

Finally, the following limitations of the present research need to be noted: First, the participants of our study were asked to recall and report on an event in the movie that elicited particularly strong emotions in them. We refrained from preselecting a film scene, because we considered that the most intense emotions may be experienced at different points of the movie by individual audience members. We found no systematic covariation between NFA and the scenes recalled as particularly emotional. However, we hope that future research will examine dynamic aspects of emotional movie experience more in-depth, and will elucidate the role of personality in shaping individuals' responses to specific aspects of movie content, aesthetics, and narrative structure.

Second, our study relied on self-report measures that tap into the subjective experience of emotions. Subjective feelings are one, but only one, of the key components of emotion (Kleinginna \& Kleinginna, 1981; Scherer, 2001). Our measures do not allow us to draw conclusions about the influence of the NFA on other emotion components. For instance, we cannot rule out that participants with a strong NFA had the same level of physiological response as other participants, and only experienced emotions more intensely due to their heightened level of emotional self-awareness. To address this issue, more research using physiological and behavioral measures of emotion is needed.

Third, participants reported on their responses to a movie they had planned to see by their own choice, consequently, self-selection was an issue. Although we are aware of the limitations associated with self-selected samples, we opted for the present approach in the interest of ecological validity. A crucial next step is to take things back to the laboratory and to verify whether the results can be replicated within the prevailing paradigm of randomly assigned exposure to media stimuli. This is important to be able to evaluate the causal 
direction of effects, and because we cannot rule out that the influence of the NFA on audiences' emotions and meta-emotions might interact with other variables that influenced individuals' decision to see the movie in the first place. At the same time, more studies of selfdetermined media use are needed, because participants' active vs. passive role in creating exposure situations may have nontrivial consequences on their motivation to indulge and enjoy emotions, or to dismiss and suppress them. 
Acknowledgments

The authors wish to thank Peter Borkenau and Roland Mangold for their helpful comments on an earlier version of this paper.

\section{Funding}

This research received no specific grant from any funding agency in the public, commercial, or not-for-profit sectors. 


\section{References}

Appel, M. (2008). Manche mögen's heiß. Ergebnisse der deutschsprachigen Version eines Instruments zur Erfassung des Emotionsmotivs. [Some like it hot. Results of the German language version of an instrument for the assessment of the need for affect.] Diagnostica, 54, 2-15.

Appel, M., \& Richter, T. (2007). Persuasive effects of fictional narratives increase over time. Media Psychology, 10, 113-134.

Appel, M. \& Richter, T. (under review). The role of Need for Affect and Transportation in narrative persuasion. A mediated moderation model.

Arnold, M. B. (1960). Emotion and personality: Vol. 1. Psychological aspects. New York: Columbia University Press.

Bartsch, A., Vorderer, P., Mangold, R., \& Viehoff, R. (2008). Appraisal of emotions in media use: Toward a process model of meta-emotion and emotion regulation. Media Psychology, 11, 7-27.

Borkenau, P., \& Ostendorf, F. (1993). NEO-Fünf-Faktoren-Inventar (NEO-FFI) nach Costa und McCrae. Göttingen: Hogrefe.

Cacioppo, J. T., \& Berntson, G. G. (1994). Relationship between attitudes and evaluative space: A critical review, with emphasis on the separability of positive and negative substrates. Psychological Bulletin, 115, 401-423.

Cohen, J., Cohen, P., West, S. G., \& Aiken, L. S. (2003). Applied multiple regression/correlation analyses for the behavioral sciences (3rd ed.). Hillsdale, NJ: Erlbaum.

Costa, P. T., \& McCrae, R. R. (1992). NEO PI-R. Professional manual. Odessa, FL: Psychological Assessment Resources. 
David, P., Horton, B., \& German, T. (2008). Dynamics of entertainment and affect in a Super Bowl audience: A multilevel approach. Communication Research, 35, 398.

Edell, J. A., \& Burke, M. C. (1987). The power of feelings in understanding advertising effects. Journal of Consumer Research, 14, 421-433

Green, M.C., \& Brock, T.C. (2000). The role of transportation in the persuasiveness of public narratives. Journal of Personality and Social Psychology, 79, 701-721.

Gross, J. J., \& Thompson, R. A. (2007). Emotion regulation: Conceptual foundations. In J.J. Gross (Ed.), Handbook of emotion regulation (pp. 3-24). New York: Guilford Press.

Haddock, G., Maio, G. R, Arnold, K. \& Huskinson, T. L. H. (2008). Should persuasion be affective or cognitive. The moderating effects of need for affect and need for cognition. Personality and Social Psychology Bulletin, 34, 769-778.

Hoffner, C., \& Levine, K. (2005). Enjoyment of Mediated Fright and Violence: A Meta-. Analysis. Media Psychology, 7, 207-237.

Huskinson, T. L. H., \& Haddock, G. (2004). Individual differences in attitude structure: Variance in the chronic reliance on affective and cognitive information. Journal of Experimental Social Psychology, 40, 82-90.

Izard, C. E., Dougherty, F. E., Bloxom, B. M., \& Kotsch, N. E. (1974). The Differential Emotions Scale: A method of measuring the meaning of subjective experience of discrete emotions. Nashville: Vanderbilt University, Department of Psychology.

John, O. P., \& Gross, J. J. (2007). Individual differences in emotion regulation. In J. J. Gross (Ed.), Handbook of emotion regulation (pp. 351-372). New York: Guilford.

Kleinginna, P. R. \& Kleinginna, A. M. (1981). A categorized list of emotion definitions, with suggestions for a consensual definition. Motivation and Emotion, 5, 345-379. 
Knobloch-Westerwick, S. (2006). Mood management: Theory, evidence, and advancements. In J. Bryant \& P. Vorderer (Eds.), The psychology of entertainment (pp. 239-254). Mahwah, NJ: Lawrence Erlbaum.

Knobloch-Westerwick, S., \& Alter, S. (2006). Mood adjustment to social situations through mass media use: How men ruminate and women dissipate angry moods. Human Communication Research, 32, 58-73.

Lang, P. J. (1980). Behavioral treatment and bio-havioral assessment: Computer applications. In J. B. Sidowski, J. H. Johnson, \& T. A. Williams (Eds.), Technology in mental health care delivery systems (pp. 119-137). Norwood: Ablex.

Larsen, J. T., McGraw, A. P., \& Cacioppo, J. T. (2001). Can people feel happy and sad at the same time? Journal of Personality and Social Psychology, 81, 684-696.

Lazarus, R. S. (1991). Emotion and adaptation. Oxford: Oxford University Press.

LeDoux, J. E. (2002). Synaptic self: How our brains become who we are. New York: Viking.

Lee, S.Y., Hwang, G., Hawkind, R. \& Pingree, S. (2008). Interplay of negative emotion and health self-efficacy on the use of health information and its outcomes. Communication Research, 35, 339-357.

Maio, G. R., \& Esses, V. M. (2001). The need for affect: Individual differences in the motivation to approach or avoid emotions. Journal of Personality, 69, 583-615.

Mares, M.-L., \& Cantor, J. (1992). Elderly viewers`responses to televised portrayals of old age. Communication Research, 19, 459-478.

Matsumoto, D. (2006). Are cultural differences in emotion regulation mediated by personality traits? Journal of Cross-Cultural Psychology, 37(4), 421-437.

Mayer, J. D., \& Gaschke, Y. N. (1988). The experience and meta-experience of mood. Journal of Personality and Social Psychology, 55, 105-111. 
Oliver, M. B. (1993). Exploring the paradox of the enjoyment of sad films. Human Communication Research, 19, 315-342.

Oliver, M. B. (2007) Appreciation as audience response: The case of tragic, poignant, and touching entertainment. In A. Bartsch, J. Eder, \& K. Fahlenbrach (Eds.), Audiovisuelle Emotionen (pp. 207-219). Köln: Halem.

Oliver, M. B., \& Bartsch, A. (in press). Appreciation as audience response: Exploring entertainment gratifications beyond hedonism. Human Communication Research.

Oliver, M., B., Limparos, A., Tamul, D., \& Woolley, J. (2009, May). The role of mixed affect in the experience of meaningful entertainment. Paper presented at the annual meeting of the International Communication Association, Chicago, IL.

Oliver, M. B., Weaver, J. B., \& Sargent, S. L. (2000). An examination of factors related to sex differences in enjoyment of sad film. Journal of Broadcasting and Electronic Media, $44,282-300$.

Renaud, D., \& Unz, D. (2006). Die M-DAS - eine modifizierte Version der Differentiellen Affekt Skala zur Erfassung von Emotionen bei der Mediennutzung. [The MDAS - a modified version of the Differential Emotion Scale for the assessment of emotions in media use.] Journal of Media Psychology, 18, 70-75.

Scherer, K. R. (2001). Appraisal considered as a process of multilevel sequential checking. In K. R. Scherer, A. Schorr \& T. Johnstone (Eds.), Appraisal processes in emotion (pp. 92120). New York: Oxford University Press.

Shen, L., \& Dillard, J. P. (2008). The influence of behavioral inhibition/approach systems and message framing on the processing of persuasive health messages. Communication Research, 34, 433-467.

Sparks, G. G. (1991). The relationship between distress and delight in males' and females' 
reactions to frightening films. Communication Research, 17, 625-637.

Tamborini, R., \& Stiff, J. (1987). Predictors of Horror Film Attendance and Appeal. An Analysis of the Audience for Frightening Films. Communication Research, 14, 415436.

Unz, D. (2006). Personal communication (e-mail, received on April, 27 $\left.{ }^{\text {th }}, 2006\right)$.

Watson, D., Clark, L. A., \& Tellegen, A. (1988). Development and validation of brief measures of positive and negative affect: The PANAS Scales. Journal of Personality and Social Psychology, 47, 1063-1070.

Zillmann, D. (1988). Mood management through communication choices. American Behavioral Scientist, 31, 327-340.

Zillman, D. (1996). The psychology of suspense in dramatic exposition. In P. Vorderer, H. J. Wulff, \& M. Friederichsen (Eds.), Suspense: Conceptualizations, theoretical analyses, and empirical explorations (pp. 199-231). Mahwah, NJ: Lawrence Erlbaum.

Zillmann, D., Weaver, J. B., Mundorf, N., \& Aust, C. F. (1986). Effects of an opposite-gender companion's affect to horror on distress, delight, and attraction. Journal of Personality and Social Psychology, 51, 586-594.

Zaleski, Z. (1984). Sensation seeking and preference for emotional visual stimuli. Personality and Individual Differences, 5, 609-611.

Zuckerman, M. (1994). Behavioral expressions and biosocial bases of sensation seeking. New York: Cambridge University Press. 


\section{Footnote}

${ }^{1}$ The idea that gratification can be derived from the experience of negative emotions is not unique to the concept of meta-emotion. It is also present in other theories of entertainment gratification including sensations seeking (Zuckerman, 1994), excitation transfer (Zillmann, 1996), downward social comparison (Mares and Cantor, 1990), and mood-adjustment (Knobloch-Westerwick \& Alter, 2006). Each of these concepts addresses the question why the experience of negative emotions can be positively evaluated by media users under certain conditions. The concept of meta-emotion is not in contrast with these more specific explanations, rather it takes one step back and asks whether the experience of emotions is positively or negatively evaluated before it poses more detailed questions about the reasons why emotions are evaluated that way. As a consequence the concept is less subject to constraints that limit applicability with regard to specific context factors such as media genres (as discussed above concerning sensation seeking and empathy), specific genre conventions (e.g., happy endings in the case of excitation transfer), or context-dependent concerns (e.g, threatened self-esteem in the case of downward social comparison, or goals such as retaliation in the case of mood-adjustment). 
Table 1:

Pearson correlations of the emotion and meta-emotion variables.

\begin{tabular}{lcccccc}
\hline & 1 & 2 & 3 & 4 & 5 & 6 \\
\hline Emotional intensity (1) & - & $-.35^{* * *}$ & $-.45^{* * *}$ & $.32 * * *$ & $-.22^{*}$ & .16 \\
Emotional valence (2) & & - & $-.49 * * *$ & -.08 & $.33^{* * *}$ & -.12 \\
Negative emotions (3) & & & - & $.32 * *$ & $-.33^{* *}$ & .01 \\
Ambivalent emotions (4) & & & & - & $.23 *$ & $.32^{* * *}$ \\
Meta-emotion enjoyment (5) & & & & & - & $.47 * *$ \\
Meta-emotion appreciation (6) & & & & & - \\
\hline
\end{tabular}

Notes. $* p<.05 ; * * p<.01 ; * * * p<.001$. For each variable, high scores represent intense emotions (1), positive valence (2), strong experience of negative emotions (3), strong experience of ambivalent emotions (4), enjoyment of emotions (5), and normative appreciation of emotions (6) 
Table 2:

Results of six hierarchical regression analyses with personality scores as predictors

\begin{tabular}{|c|c|c|c|c|c|c|c|c|c|}
\hline \multirow[b]{3}{*}{ Predictors } & \multicolumn{9}{|c|}{ Criteria } \\
\hline & \multicolumn{3}{|c|}{ emotion intensity } & \multicolumn{3}{|c|}{ emotional valence } & \multicolumn{3}{|c|}{ negative emotions } \\
\hline & $\mathrm{B}$ & SE B & $\beta$ & $\mathrm{B}$ & SE B & $\beta$ & $\mathrm{B}$ & SE B & $\beta$ \\
\hline \multicolumn{10}{|c|}{ Step 1} \\
\hline Gender & -0.01 & 0.11 & -0.01 & 0.02 & 0.11 & 0.02 & 0.04 & 0.10 & 0.04 \\
\hline Film & -0.05 & 0.10 & -0.05 & 0.11 & 0.10 & 0.12 & -0.30 & 0.09 & $-0.33 *$ \\
\hline \multicolumn{10}{|c|}{ Step 2} \\
\hline Extraversion & 0.07 & 0.21 & -0.03 & 0.42 & 0.22 & 0.21 & -0.04 & 0.19 & -0.02 \\
\hline Neuroticism & -0.00 & 0.17 & -0.00 & 0.14 & 0.18 & 0.10 & 0.27 & 0.16 & 0.20 \\
\hline Openness & 0.30 & 0.16 & 0.17 & -0.04 & 0.17 & -0.03 & 0.11 & 0.15 & 0.07 \\
\hline Agreeableness & 0.16 & 0.22 & 0.06 & -0.52 & 0.23 & $-0.22 *$ & 0.24 & 0.20 & 0.11 \\
\hline Conscientiousness & 0.43 & 0.15 & $0.26 * *$ & -0.20 & 0.16 & -0.13 & 0.33 & 0.14 & $0.23 *$ \\
\hline \multicolumn{10}{|c|}{ Step 3} \\
\hline NFA approach & 0.41 & 0.12 & $0.44 * *$ & -0.38 & 0.12 & $-0.42 * *$ & 0.21 & 0.11 & $0.26 *$ \\
\hline NFA avoidance & 0.26 & 0.11 & $0.27 *$ & -0.13 & 0.12 & -0.15 & 0.11 & 0.10 & 0.13 \\
\hline
\end{tabular}


Table 2. (continued)

\begin{tabular}{|c|c|c|c|c|c|c|c|c|c|}
\hline \multirow[b]{3}{*}{ Predictors } & \multicolumn{9}{|c|}{ Criteria } \\
\hline & \multicolumn{3}{|c|}{ ambivalent emotions } & \multicolumn{3}{|c|}{ meta-emotions: enjoyment } & \multicolumn{3}{|c|}{ meta-emotions: normative } \\
\hline & $\mathrm{B}$ & SE B & $\beta$ & $\mathrm{B}$ & SE B & $\beta$ & $\mathrm{B}$ & SE B & $\beta$ \\
\hline \multicolumn{10}{|c|}{ Step 1} \\
\hline Gender & 0.19 & 0.09 & $0.20 *$ & 0.12 & 0.11 & 0.11 & 0.00 & 0.07 & 0.00 \\
\hline Film & 0.01 & 0.08 & 0.01 & 0.16 & 0.10 & 0.16 & 0.00 & 0.06 & 0.00 \\
\hline \multicolumn{10}{|c|}{ Step 2} \\
\hline Extraversion & 0.36 & 0.17 & $0.21 *$ & -0.01 & 0.21 & -0.00 & -0.12 & 0.13 & -0.10 \\
\hline Neuroticism & 0.51 & 0.14 & $0.38 * *$ & 0.18 & 0.18 & 0.12 & -0.05 & 0.11 & -0.06 \\
\hline Openness & 0.09 & 0.13 & 0.06 & -0.01 & 0.16 & -0.01 & 0.12 & 0.10 & 0.12 \\
\hline Agreeableness & 0.01 & 0.18 & 0.00 & -0.54 & 0.23 & $-0.22 *$ & -0.04 & 0.14 & -0.03 \\
\hline Conscientiousness & 0.20 & 0.12 & 0.14 & -0.39 & 0.16 & $-0.24^{*}$ & -0.21 & 0.09 & $-0.21 *$ \\
\hline \multicolumn{10}{|c|}{ Step 3} \\
\hline NFA approach & 0.27 & 0.10 & $0.34 * *$ & -0.02 & 0.12 & -0.02 & 0.19 & 0.07 & $0.33^{*}$ \\
\hline NFA avoidance & -0.01 & 0.09 & -0.02 & -0.44 & 0.11 & $-0.48 * * *$ & -0.16 & 0.07 & $-0.28 *$ \\
\hline
\end{tabular}

Notes. $* p<.05 ; * * p<.01 ; * * *<<.001$. Weighted effects codes were used for the categorical variables movie and gender with $1=$

The Omen, $-0.83=$ United 93, and $1=$ male, $-0.75=$ female, which followed the calculus of $-\mathrm{n}_{1} / \mathrm{n}_{2}$ (cf. Cohen et al., 2003). The

Need for Affect scores were $z$-standardized. 
The complete regression equation included step 1: Gender and film viewed; step 2: Big Five scales; step 3: Need for Affect; step 4: All interaction effects between gender, film, and the NFA-scales. The table shows selected regression weights for the complete equation.

Increments emotion intensity, step $1: R^{2}=.02, F(2,115)=0.9, p>.30 ;$ step $2: \Delta R^{2}=.20, F_{\text {change }}(5,110)=5.7, p<.001 ;$ step $3: \Delta R^{2}$ $=.12, F_{\text {change }}(2,108)=9.4, p<.001 ;$ step $4: \Delta R^{2}=.05, F_{\text {change }}(11,97)=0.8, p>.60$. Increments emotional valence, step $1: R^{2}=$ $.01, F(2,115)=0.6, p>.50 ;$ step $2: \Delta R^{2}=.09, F_{\text {change }}(5,110)=2.1, p=.07 ;$ step $3: \Delta R^{2}=.08, F_{\text {change }}(2,108)=5.3, p<.01 ;$ step 4 : $\Delta R^{2}=.05, F_{\text {change }}(11,97)=0.6, p>.80$. Increments negative emotions, step $1: R^{2}=.08, F(2,115)=5.3, p<.01 ;$ step $2: \Delta R^{2}=.15$, $F_{\text {change }}(5,110)=4.2, p<.01 ;$ step $3: \Delta R^{2}=.03, F_{\text {change }}(2,108)=2.2, p=.12 ;$ step $4: \Delta R^{2}=.03, F_{\text {change }}(11,97)=0.3, p>.90$. Increments ambivalent emotions, step $1: R^{2}=.01, F(2,115)=0.5, p>.60 ;$ step $2: \Delta R^{2}=.29, F_{\text {change }}(5,110)=9.0, p<.001 ;$ step 3 : $\Delta R^{2}=.06, F_{\text {change }}(2,108)=5.1, p<.001 ;$ step $4: \Delta R^{2}=.05, F_{\text {change }}(11,97)=0.7, p>.70$. Increments meta-emotion enjoyment, step $1: R^{2}=.05, F(2,115)=3.0, p=.05 ;$ step $2: \Delta R^{2}=.07, F_{\text {change }}(5,110)=1.8, p=.11 ;$ step $3: \Delta R^{2}=.11, F_{\text {change }}(2,108)=7.9, p<.01$; step 4: $\Delta R^{2}=.05, F_{\text {change }}(11,97)=0.6, p>.80$. Increments meta-emotion normative appreciation, step $1: R^{2}=.01, F(2,115)=0.2$, $p>.70 ;$ step $2: \Delta R^{2}=.11, F_{\text {change }}(5,110)=5.7, p<.05 ;$ step $3: \Delta R^{2}=.16, F_{\text {change }}(2,108)=11.8, p<.001 ;$ step $4: \Delta R^{2}=.07, F_{\text {change }}$ $(11,97)=0.9, p>.50$. 